\title{
Endoscopic and endoscopic ultrasound (EUS) features of annular pancreas: duodenal ulceration and a dilated bile duct
}

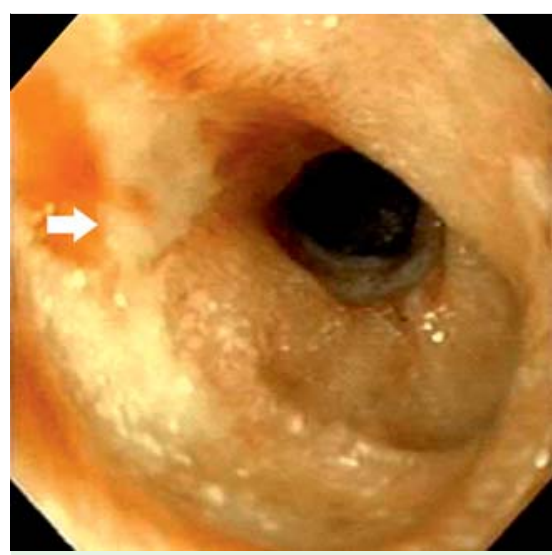

Fig. 1 Esophagogastroduodenoscopy in a 70-year-old man with severe anemia showing luminal narrowing in the second part of the duodenum and a duodenal ulcer (arrow).

Annular pancreas is a rare congenital anomaly in which a ring of pancreatic tissue encircles the second part of the duodenum [1]. Here we present the endoscopic findings in two patients with annular pancreas, including the first endoscopic ultrasound (EUS) video to be published of the condition, illustrating the pancreatic duct coursing around the duodenum.

Our first patient was a 70-year-old man who presented with severe anemia. Esophagogastroduodenoscopy showed narrowing of the second part of the duodenum with ulceration and contact bleeding ( Fig. 1). Biopsies did not reveal any malignancy or evidence of Helicobacter pylori infection. Abdominal computed tomography (CT) showed a ring of pancreas encircling the duodenum ( $\bullet$ Fig. 2 ). The patient was discharged with a prescription for omeprazole. At follow-up more than a year later, there was no outlet obstruction and the anemia had resolved. Magnetic resonance imaging (MRI) confirmed the presence of annular pancreas (๑ Fig. 3).

Our second patient was a 59-year-old man with Ogilvie's syndrome. Abdominal $\mathrm{CT}$ revealed a $15-\mathrm{mm}$ dilated common bile duct (CBD) along with dilated bowel loops. Liver function tests were normal. Radial EUS evaluation of the biliary tree did not show any stone or stricture, but the pancreas and pancreatic duct were

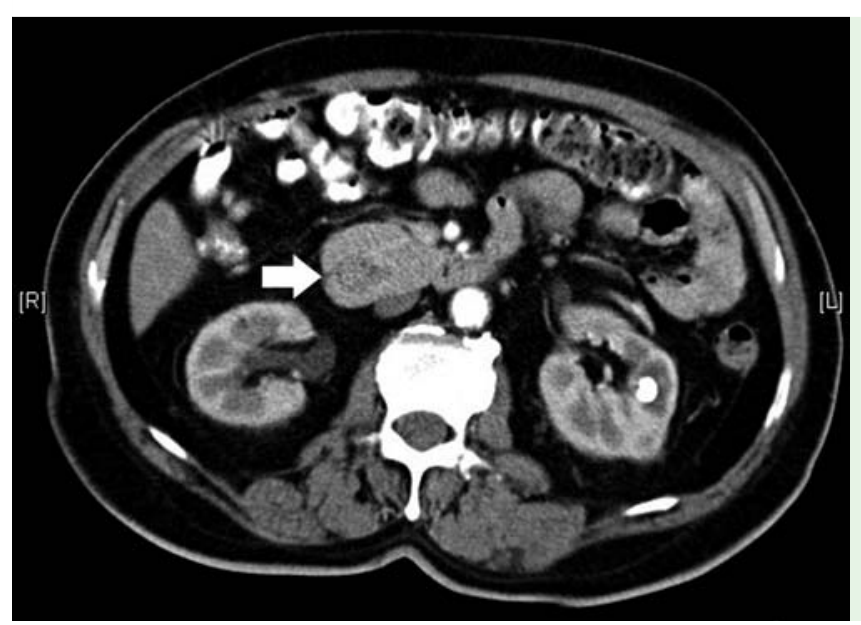

Fig. 2 Abdominal computed tomography (CT) scan of the same patient as in $\bullet$ Fig. 1. The hypodense area depicts the pancreatic head (arrow) forming a ring around the collapsed duodenum. Serial sections indicated that the hypodense area was in continuity with the first part of the duodenum and did not represent a pancreatic lesion.

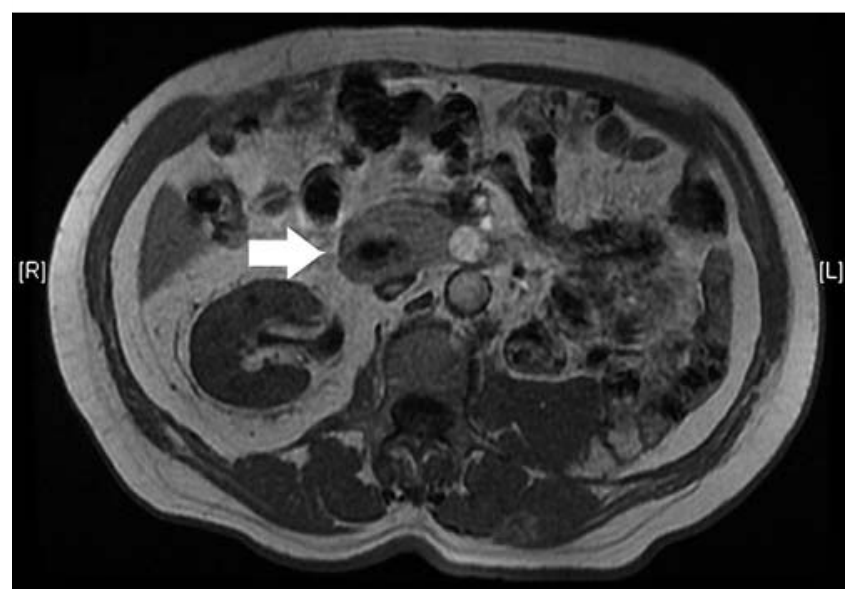

Fig. 3 Abdominal magnetic resonance (MR) image of the same patient as in $\bullet$ Fig. 1. A ring of pancreas is seen encircling the second part of the duodenum (arrow).

seen encircling the second part of the duodenum and merging with the distal CBD at the ampulla ( Fig.4, Video 1 ). The dilated CBD was attributed to the annular pancreas.

Annular pancreas was first described by Tiedemann in 1818 and named by Ecker in 1862 [2]. It results from the failure of the ventral anlage of the pancreas to rotate with the duodenum during gestation.

\section{Video 1}

Radial endoscopic ultrasound (EUS) (duodenum). The dilated common bile duct (CBD) is seen medial to the portal vein (PV). Pancreatic parenchyma surrounds the duodenum lumen with the hypoechoic pancreatic duct (PD) coursing from the genu at the PV, around the transducer (counterclockwise direction) to 11 o'clock, where the CBD and ampulla are located.
Symptomatic anemia and a dilated CBD are extremely rare presentations of annular pancreas $[3,4]$. The diagnosis of this condition can be confirmed by EUS, CT, or MRI [5].

Endoscopy_UCTN_Code_CCL_1AF_2AZ_3AD

Competing interests: None

\section{E. W. L. Wee ${ }^{1}$, N. M. Varghese ${ }^{1}$,} M. L. Tung ${ }^{2}$, H. C. Low ${ }^{2}$

${ }^{1}$ Division of Gastroenterology, Department of General Medicine, Khoo Teck Puat Hospital, Singapore

${ }^{2}$ Division of Gastroenterology and Hepatology, National University Hospital, Singapore 

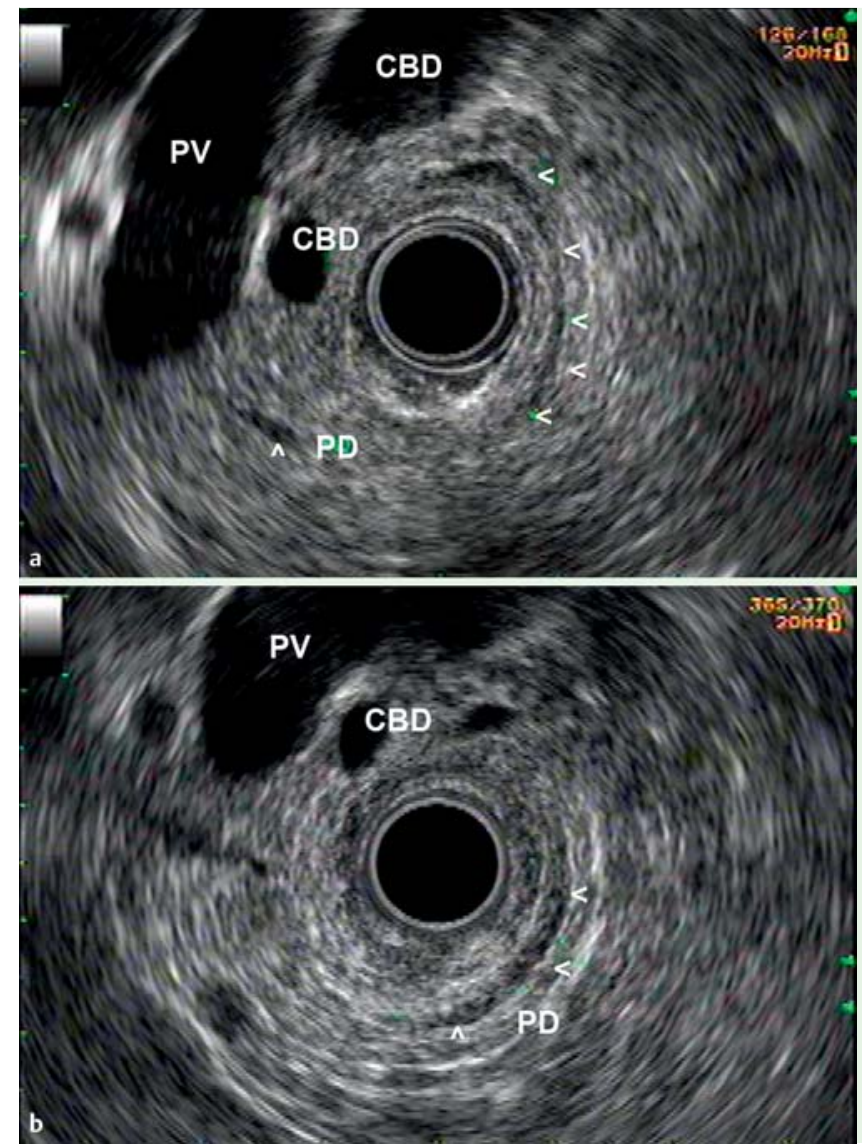

Fig. 4 a, b Endoscopic ultrasound (EUS) view of the second part of the duodenum. The dilated common bile duct (CBD) is seen lying medial to the portal vein $(\mathrm{PV})$ and the pancreatic parenchyma is encircling the transducer. The pancreatic duct (PD) is seen intermittently coursing from the genu at 8 o'clock around the transducer in a counterclockwise fashion to the 12 o'clock position (arrowheads).

\section{References}

1 Jadvar H, Mindelzun RE. Annular pancreas in adults: imaging features in seven patients. Abdom Imaging 1999; 24 (Suppl. 02): 174 177

2 Ecker A. Bildungsfehler des Pankreas und des Herzens. Z Rat Med 1862; 14: 354

3 Green JD, Fieber SS, Buniak B. Annular pancreas with dilated biliary and pancreatic ducts. Am J Gastroenterol 1993; 88 (Suppl. 03): 467-468

4 Naylor RG, Juler GL. Congenital causes of duodenal ulcers in adults. Arch Surg 1976; 111 (Suppl. 06): 658-662

5 Lee NK, Kim S, Jeon TY et al. Complications of congenital and developmental abnormalities of the gastrointestinal tract in adolescents and adults: evaluation with multimodality imaging. Radiographics 2010; 30 : 1489-1507

\section{Bibliography}

DOI http://dx.doi.org/

10.1055/s-0032-1325775

Endoscopy 2012; 44: E417-E418

(c) Georg Thieme Verlag KG

Stuttgart · New York

ISSN 0013-726X

\section{Corresponding author}

\section{DrE. W. L. Wee}

Division of Gastroenterology

Department of General Medicine

Khoo Teck Puat Hospital

90 Yishun Central

Singapore 768828

Fax: +65-6602-3700

Wee1976@gmail.com 